\title{
Canadian Urological Association recommendations on prostate cancer screening and early diagnosis
}

\author{
Ricardo A. Rendon, $M D^{1}$; Ross J. Mason, $M D^{2}$; Karim Marzouk, $M D^{3}$; Antonio Finelli, $M D^{4}$; Fred Saad, $M D^{5}$;

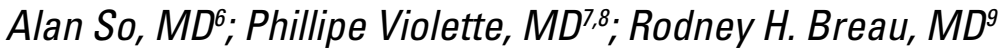

'Department of Urology, Dalhousie University, Halifax, NS, Canada; ${ }^{2}$ Department of Urology, Mayo Clinic, Rochester, MN, United States; ${ }^{3}$ Division of Urology, Memorial Sloan Kettering Cancer Centre, New York, NY, United States; ${ }^{\circ}$ Division of Urology, University of Toronto, Toronto, ON, Canada; ${ }^{5}$ Department of Surgery (Urology), University of Montreal, Montreal, QC, Canada; ${ }^{6}$ Department of Urologic Sciences, University of British Columbia, Vancouver, BC, Canada; ${ }^{7}$ Department of Surgery, Western University, London, ON, Canada; ${ }^{8}$ Departments of Surgery and Health Research Methods, Evidence, and Impact, McMaster University, Hamilton, ON, Canada; ' $D$ Division of Urology, University of Ottawa, Ottawa, ON, Canada

Cite as: Can Urol Assoc J 2017;11(10):298-309. http://dx.doi.org/10.5489/cuaj.4888

See related editorial on page 295

\section{Introduction}

Prostate cancer remains the most commonly diagnosed noncutaneous malignancy among Canadian men and is the third leading cause of cancer-related death. In 2016, an estimated 21600 men were diagnosed with prostate cancer and 4000 men died from the disease; ${ }^{1}$ however, prostate cancer is a heterogeneous disease with a clinical course ranging from indolent to life-threatening.

Identifying and treating men with clinically significant prostate cancer while avoiding the over-diagnosis and overtreatment of indolent disease remains a significant challenge. Several professional associations have developed guidelines on prostate cancer screening and early diagnosis, but there are conflicting recommendations on how best to approach these issues. With recent updates from several large, randomized, prospective trials, as well as the emergence of several new diagnostic tests, the Canadian Urological Association (CUA) has developed these evidence-based recommendations to guide clinicians on prostate cancer screening and early diagnosis for Canadian men. The aim of these recommendations is to provide guidance on the current best prostate cancer screening and early diagnosis practices and to provide information on new and emerging diagnostic modalities.

\section{Evidence synthesis and recommendations development}

In order to develop these recommendations, the following questions related to prostate cancer screening and diagnosis were defined, a priori, to guide the specific literature searches and evidence synthesis:
1. Should Canadian men undergo prostate cancer screening?

2. At what age should prostate cancer screening begin?

3. When can prostate cancer screening be stopped?

4. How frequently should prostate cancer screening be performed?

5. What diagnostic tests, in addition to prostate-specific antigen (PSA), are available for the early diagnosis of prostate cancer?

The aim of answering the first four questions is to provide guidance on prostate cancer screening in general. The aim of the fifth question is to provide information on additional available tests. Therefore, a different search strategy was used for these questions. For the first four questions, we employed a two-step approach in order to synthesize the best available evidence to develop these recommendations. First, recognizing that several other professional organizations have developed evidence-based guidelines on prostate cancer screening and diagnosis, a complete bibliographic review of existing guidelines on prostate cancer screening and diagnosis was performed. Studies related to questions 1-4 were reviewed at full length. Second, in order to identify studies not captured by existing guidelines, a search of the literature was conducted using MEDLINE to identify articles related to the screening and diagnosis of prostate cancer that were published between January 1, 2016 and February 2,2017 . To identify articles not yet indexed, a search was also performed using PubMed without MEDLINE filters (see Appendix 1 for search strategy). For the fifth question related to additional diagnostic tests beyond PSA, which can potentially aid in the early detection of prostate cancer, a systematic search was performed in a similar fashion with no date restriction for tests not covered by existing guidelines.

Case series, case reports, non-systematic reviews, editorials, and letters to the editor were excluded and the search strategy was restricted to English language articles. Trained methodologists implemented the specific search 
strategy and two authors reviewed the titles and abstracts of potential studies to identify their relevance for full-text review. Levels of evidence and grades of recommendation are provided according to the International Consultation on Urologic Diseases modification of the 2009 Oxford Centre for Evidence-Based Medicine grading system. ${ }^{2}$

\section{PSA screening}

1. The CUA suggests offering PSA screening to men with a life expectancy greater than 10 years. The decision of whether or not to pursue PSA screening should be based on shared decision-making after the potential benefits and harms associated with screening have been discussed (Level of evidence: 1; Grade of recommendation: B).

Justification: Prostate cancer screening is one of the most controversial issues in urology and preventative medicine. With varying recommendations on PSA screening, no consensus is established among several professional and government organizations (Supplementary Table 1). Many professional associations, including the American Urological Association, ${ }^{3}$ National Comprehensive Cancer Network, ${ }^{4}$ European Association of Urology, ${ }^{5}$ and the American College of Physicians ${ }^{6}$ recommend offering PSA screening to interested men after a thorough discussion of the benefits and harms. In addition, the United States Preventative Services Task Force (USPSTF) recently recommended a similar shared decision-making approach in men aged 55-69 (currently in draft form at the time of this publication) after previously recommending against screening. ${ }^{7}$ Conversely, the Canadian Task Force on Preventative Health Care (CTFPHC) weakly recommends against PSA screening in men of any age; ${ }^{8}$ however, several important updates of large, populationbased studies have been released since the time of this task force publication and herein we include a summary of the evidence for and against screening for prostate cancer.

There have been six randomized, controlled trials investigating the role of PSA screening in adult men; ${ }^{9-14}$ however, three of these studies are at significant risk of bias and are generally not considered when weighing the evidence for or against prostate cancer screening. Thus, three randomized, controlled trials, all with recent updates, constitute the credible Level 1 evidence concerning prostate cancer screening; the Prostate, Lung, Colon, and Ovarian screening trial (PLCO), ${ }^{9}$ the European Randomized Study of Screening for Prostate Cancer (ERSPC), ${ }^{10}$ and the Goteborg randomized trial of PSA screening (Table 1). ${ }^{11}$

The PCLO was a North American trial including 76683 men aged 55-74 accrued from 10 centres where subjects were randomized to organized screening or standard care. ${ }^{9}$ In the recently published update, with 15 years of followup, there continues to be no difference in prostate cancer-specif-

\begin{tabular}{|c|c|c|c|}
\hline & $\begin{array}{c}\text { PLCO } \\
(2017 \text { update })^{15}\end{array}$ & $\begin{array}{c}\text { ERSPC } \\
(2014 \text { update })^{16}\end{array}$ & $\begin{array}{c}\text { Goteborg } \\
(2014 \text { update })^{17}\end{array}$ \\
\hline $\mathrm{n}$ & 76683 & 162243 & 20000 \\
\hline Age & $55-74$ & $55-69$ & $50-64$ \\
\hline Site & 10 US centres & $\begin{array}{l}8 \text { European } \\
\text { countries }\end{array}$ & $\begin{array}{c}1 \text { city (Goteborg, } \\
\text { Sweden) }\end{array}$ \\
\hline Intervention & $\begin{array}{l}\text { PSA annually } x \\
6 \text { years Annual } \\
\text { DRE x } 4 \text { years }\end{array}$ & $\begin{array}{l}\text { PSA q4 years } \\
\text { (in most } \\
\text { centres) } \\
\text { Some centres } \\
\text { offered DRE }\end{array}$ & PSA q2 years \\
\hline $\begin{array}{l}\text { Current } \\
\text { median } \\
\text { followup }\end{array}$ & 15 years & 13 years & 18 years \\
\hline $\begin{array}{l}\text { Definition } \\
\text { of positive } \\
\text { test }\end{array}$ & $\begin{array}{l}\text { PSA }>4 \mathrm{ng} / \mathrm{ml} \\
\text { Abnormal DRE }\end{array}$ & $\begin{array}{l}\mathrm{PSA}>3 \mathrm{ng} / \mathrm{ml} \\
\text { (most centres) }\end{array}$ & $\begin{array}{c}\text { PSA }>2.5 \mathrm{ng} / \mathrm{ml} \\
\text { (from } 2005 \mathrm{on} \text { ) } \\
\text { PSA }>2.9 \mathrm{ng} / \mathrm{ml} \\
\text { (from } 1999-2004 \text { ) } \\
\text { PSA }>3.4 \mathrm{ng} / \mathrm{ml} \\
\text { (from 1995-98) }\end{array}$ \\
\hline $\begin{array}{l}\text { Prostate } \\
\text { cancer } \\
\text { deaths }\end{array}$ & $\begin{array}{l}\text { Control: } 244 \\
\text { Screened: } 255\end{array}$ & $\begin{array}{l}\text { Control: } 545 \\
\text { Screened: } 355\end{array}$ & $\begin{array}{l}\text { Control: } 122 \\
\text { Screened: } 79\end{array}$ \\
\hline & & $0.79(0.69-0.91)$ & $0.58(0.46-0.72)$ \\
\hline $\begin{array}{l}\text { Rate ratio } \\
\text { for CSS } \\
(95 \% \mathrm{Cl})\end{array}$ & $1.04(0.87-1.24)$ & $\begin{array}{l}21 \% \text { relative } \\
\text { risk reduction } \\
\text { in favour of } \\
\text { screening }\end{array}$ & $\begin{array}{l}42 \% \text { relative } \\
\text { risk reduction } \\
\text { in favour of } \\
\text { screening }\end{array}$ \\
\hline NNS & N/A & $1: 781$ & $1: 139$ \\
\hline NND & $\mathrm{N} / \mathrm{A}$ & 1:27 & 1:13 \\
\hline
\end{tabular}

CSS: Prostate cancer-specific survival; DRE: digital rectal exam; ERSPC: European

Randomized Study of Screening for Prostate Cancer; NNS: number needed to screen; NND: number needed to diagnose; PLCO: Prostate, Lung, Colon, and Ovarian screening trial; PSA: prostate-specific antigen.

ic mortality between patients in the intervention (screening) and control arms; ${ }^{15}$ however, several important limitations may mitigate this finding. Foremost, there was considerable contamination between study arms, with over $80 \%$ of subjects in the control arm having at least one PSA measurement during the study period. This high contamination rate biases the result toward finding no difference in mortality from prostate cancer.

The ERSPC study is a collection of randomized trials conducted across eight European countries and includes 162243 men aged 55-69. While there were some differences between the individual trials, men were randomized to organized PSA screening or standard care. ${ }^{10}$ With 13 years of followup, there was a $21 \%$ relative risk reduction in prostate cancer mortality. ${ }^{16}$ In terms of absolute risk reduction, this equates to 1.28 less prostate cancer deaths for every 1000 men screened or 781 men undergoing screening and 27 men undergoing treatment to prevent one prostate cancer death. In the Swedish Goteborg study of 20000 patients aged 50-64 at enrollment, a similar 
reduction in prostate cancer mortality was seen at up to 18 years of followup, with a relative risk reduction of $42 \%$ and 139 patients being invited for screening to prevent one prostate cancer death. ${ }^{17}$ Although there was also contamination of the control arms in both the ERSPC and Goteborg trials, the estimated proportion of control patients receiving PSA testing is significantly lower than those in the PLCO trial. ${ }^{11,18,19}$ Overall, based on currently available evidence from randomized, controlled trials, it appears as though organized PSA screening results in a reduction in prostate cancer mortality. To add to these currently available studies, the initial results from the cluster randomized trial of PSA testing for prostate cancer (CAP trial), a large randomized trial including over 400000 patients in the U.K. randomized to PSA screening or standard care, will likely provide further information on the effects of PSA screening in the near future. ${ }^{20}$

There is also weaker evidence from epidemiological studies on the effect of PSA screening. Prostate cancer mortality has declined since the introduction of PSA screening in North America. ${ }^{21-23}$ While we cannot know with certainty why mortality has declined, modelling studies indicate that the most plausible and largest contribution to mortality reduction is from screening. ${ }^{23-27}$ Additionally, there has been a decrease in the incidence of prostate cancer diagnosis in recent years in the U.S., which is likely a result of decreased screening use. ${ }^{28-30}$ This has been associated with a stage migration towards higher stage and more frequent metastatic disease. ${ }^{30,31}$ While more time is required to determine whether this recent stage migration will result in an increase in prostate cancer mortality, we believe that reducing the morbidity of advanced and metastatic prostate cancer is in itself an important outcome. Although these observations were not directly used by the guideline panel when considering recommendation for PSA screening, the underlying risk of under-diagnosis of high-risk disease remains a concern.

Although the available evidence suggests there are benefits to prostate cancer screening in terms of reduction in mortality, there are also significant potentials harms of overdiagnosis and over-treatment. Indeed, up to $67 \%$ of men diagnosed with prostate cancer by screening will be identified as having clinically insignificant prostate cancer, which, if never detected, would be unlikely to lead to increased morbidity or mortality. ${ }^{32-36}$ Thus, if screened, men with insignificant disease may be unnecessarily exposed to the potential harms of both prostate biopsy and treatment in addition to the psychological effects accompanying a prostate cancer diagnosis. The increased use of active surveillance for lowrisk prostate cancer in Canada has been an important step in reducing the over-treatment of prostate cancer; however, active surveillance does not eliminate the issue of overdiagnosis and itself is associated with significant potential detriments to quality of life. ${ }^{37}$ With these risks in mind, it is imperative that we not only separate the diagnosis of prostate cancer from the treatment of prostate cancer, but that we institute improved screening and early detection practices to decrease the risk of detecting clinically insignificant disease.

The CUA recognizes that PSA screening may not be the best option for all men. Balancing the known benefits and risks of PSA screening is difficult and is significantly influenced by personal values. As such, the decision of whether or not to undergo prostate cancer screening is, and will likely remain, an individualized decision. In order to reach this decision, the CUA recommends that healthcare providers engage in a thorough discussion on the potential risks and benefits of PSA screening with their patients and that shared decision-making be performed.

\section{Best screening practices}

When prostate cancer screening is performed, the overarching goal should be the early detection of clinically significant prostate cancer in healthy men while minimizing the detection and treatment of low-risk disease. Screening studies are challenging to conduct because of the large numbers of participants required, risk of contamination, loss to followup, and many other pitfalls. It is not feasible to evaluate most questions regarding timing and administration of PSA directly. In this context, the CUA provides the following recommendations based upon the inclusion criteria of randomized trials and high-quality observational studies to encourage "smart" screening. Our aims are to maintain benefits and mitigate potential harms associated with screening.

2. For men electing to undergo PSA screening, we suggest starting PSA testing at age 50 in most men and at age 45 in men at an increased risk of prostate cancer (Level of evidence: 3; Grade of recommendation: $C$ ).

Justification: Although the optimal age for starting PSA screening has not been vigorously studied, our recommendation for starting PSA screening at age 50 comes from the Goteborg trial, which provides randomized data on the benefits of screening in men starting at this age; ${ }^{11}$ however, evidence from observational studies suggests that certain men may benefit from PSA screening at an earlier age, with a nearly $5 \%$ risk of developing lethal prostate cancer within 15 years for men aged $45-49$ with a PSA $>4 \mathrm{ng} / \mathrm{ml} .^{38,39}$ Although it remains unclear which men will benefit from early PSA screening, family history imparts a substantially increased risk of prostate cancer diagnosis at a younger age. Particularly, men aged $<50$ with a family history of prostate cancer in a first- or second-degree relative have an approximately five-fold and two-fold increased risk of receiving a prostate cancer diagnosis, respectively. ${ }^{38}$

The potential benefits and harms of PSA screening for men less than age 45 has not been prospectively studied; 
however, a recently published case-control study nested within the Physicians Health Study cohort identified that the risk of developing metastatic prostate cancer within 15 years among men in this age group was very low, even among men with PSA levels in the top decile. ${ }^{38}$ Thus, PSA testing in these men may lead to biopsies and diagnoses that are unlikely to provide benefit. The potential delay in diagnosis in the small proportion of men at this age with clinically significant prostate cancer seems unlikely to lead to a missed opportunity for curative treatment.

These recommendations are not directed towards men with known germ-line mutations associated with prostate cancer development (e.g., BRCA1, BRCA2, HOXB13). In these cases, an individualized testing strategy after consultation with a clinical geneticist is most appropriate.

3. For men electing to undergo PSA screening, we suggest that the intervals between testing should be individualized based on previous PSA levels (Fig. 1).

a. For men with PSA $<1 \mathrm{ng} / \mathrm{ml}$, repeat PSA testing every four years (Level of evidence: 3 ; Grade of recommendation: $C$ ).

b. For men with PSA 1-3 ng/ml, repeat PSA testing every two years (Level of evidence: 3 ; Grade of recommendation: $C$ ).

c. For men with PSA $>3 \mathrm{ng} / \mathrm{ml}$, consider more frequent PSA testing intervals or adjunctive testing strategies (Level of evidence: 4; Grade of recommendation: $C$ ).

Justification: Although the frequency at which PSA screening should be performed has not been rigorously studied to date, we can extrapolate from the existing clinical trials and observational studies to provide some guidance on this issue. In particular, men in the screening arms of the ERSPC trial and Goteborg trial underwent testing at intervals of four and two years, respectively, providing the basis for our recommendations.

For men with a PSA level $<1 \mathrm{ng} / \mathrm{ml}$, longer intervals between PSA testing are appropriate. Indeed, a large prospective cohort study including men undergoing annual PSA screening identified that men with a PSA $<1 \mathrm{ng} / \mathrm{ml}$ had a 10 -year prostate cancer detection rate of only $3.4 \%$, of which $90 \%$ were considered low-risk. ${ }^{40}$ Furthermore, the nested case-control study referenced above identified that the risk of developing metastatic disease within 15 years for a man of any age with PSA $<1 \mathrm{ng} / \mathrm{ml}$ is very low. ${ }^{39}$ As such, allowing a longer interval between PSA testing for these men is unlikely to result in an increase in prostate cancer morbidity or mortality and will potentially reduce the risk of over-detection as a result of leadtime bias or natural fluctuations in PSA levels.

On the other hand, as baseline PSA levels rise above 1 $\mathrm{ng} / \mathrm{ml}$, the intermediate-term risk of developing both any prostate cancer and clinically significant prostate cancer increases substantially. ${ }^{39-41}$ As such, we recommend that these men, if electing PSA screening, should undergo testing every two years. The ERSPC trial considered a positive test to be a PSA level of $3 \mathrm{ng} / \mathrm{ml}$, while the Goteborg trial considered a positive test to be between 2.5 and $3.4 \mathrm{ng} / \mathrm{ml}$ (depending on the year of study). Thus, the optimal frequency of PSA testing in men above these levels is unknown. For men with PSA $>3 \mathrm{ng} / \mathrm{ml}$, more frequent PSA testing intervals can be considered. In addition, adjunctive testing strategies that estimate the risk of clinically significant disease may be helpful for biopsy decision-making in these men (see below).

4. For men electing to undergo PSA screening, we suggest that the age at which to discontinue PSA screening should be based on current PSA level and life expectancy.

a. For men aged 60 with a PSA $<1 \mathrm{ng} / \mathrm{ml}$, consider discontinuing PSA screening (Level of evidence: 2; Grade of recommendation: C).

b. For all other men, discontinue PSA screening at age 70 (Level of evidence: 2; Grade of recommendation: $C$ ).

c. For men with a life expectancy less than $\mathbf{1 0}$ years, discontinue PSA screening (Level of evidence: 4; Grade of recommendation: $C$ ).

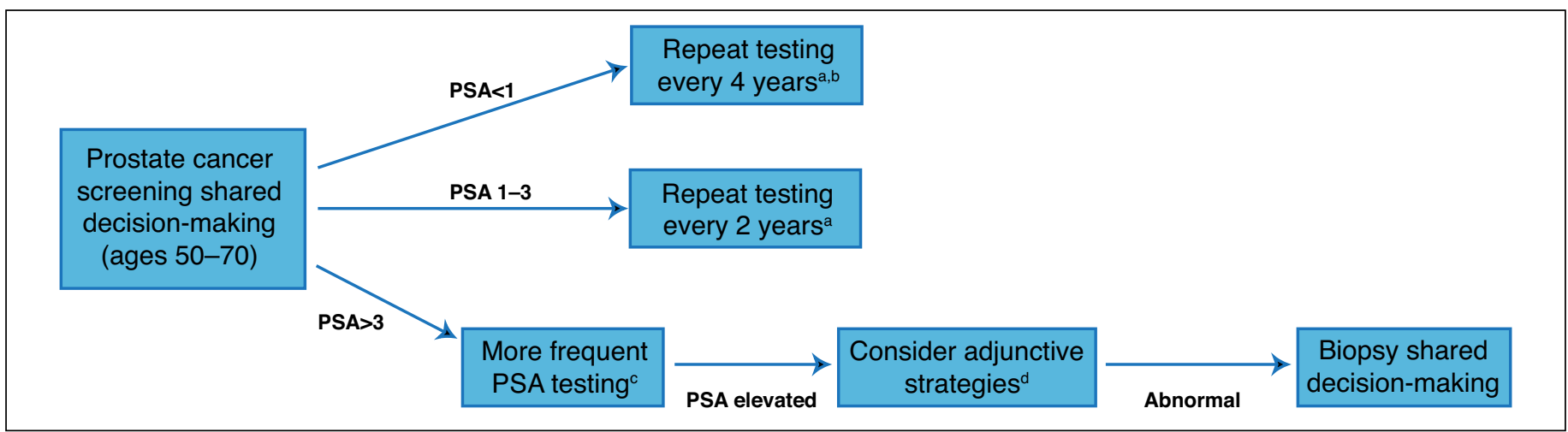

Fig. 1. Prostate cancer screening pathway. ${ }^{a}$ Discontinue screening if life expectancy $<10$ years; ${ }^{b}$ consider discontinuation of screening if age $>60$ and PSA $<1 \mathrm{ng} / \mathrm{ml}$; ${ }^{\circ}$ more frequent testing interval can be considered; the optimal frequency is unknown; di.e., risk calculators, \% free PSA, etc. PSA: prostate-specific antigen. 
Justification: For men at age 60 with a PSA level $<1 \mathrm{ng} / \mathrm{ml}$, the risk of developing or dying from metastatic prostate cancer is low. ${ }^{39,42,43}$ In a large, population-based study comparing two cohorts of men (one screened and one unscreened), the 15-year cumulative incidence of metastatic prostate cancer was low in both cohorts among men with a PSA $<1 \mathrm{ng} / \mathrm{ml}$ at age $60\left(0.4 \%\right.$ and $0 \%$, respectively).$^{42}$ In addition, a casecontrol study nested within the unscreened cohort found that the risk of being diagnosed with metastatic prostate cancer by age 85 was $0.5 \%$ for men with a PSA $<1 \mathrm{ng} / \mathrm{ml}$ at age $60 .{ }^{43}$ In contrast, for men at this age with a PSA above $1 \mathrm{ng} / \mathrm{ml}$, the risk of developing potentially lethal prostate cancer increases substantially according to PSA level and thus screening can reasonably be continued.

Men at age $>70$ have the highest incidence of prostate cancer over-diagnosis and several studies have suggested that screening in this age group is likely not beneficial. ${ }^{16,27,44}$ Indeed, a large population-based study identified that the risk of prostate cancer over-diagnosis increases substantially with age and is highest in men greater than age 70 . Additionally, the ERSPC trial identified that starting screening at age $>70$ did not result in a reduction in prostate cancer mortality. ${ }^{16}$ Furthermore, a well-performed modelling study using data from the ERSPC found that any potential benefit to screening in men over 70 was offset by the detriments to quality of life. ${ }^{27}$ Thus, we recommend that PSA testing in asymptomatic men be discontinued at age 70; however, for interested men in excellent health at age 70, PSA testing can be considered, recognizing the lack of empirical data in this age group. As such, for these men, continued PSA testing is a matter of clinical judgment and personal preferences.

For men with a high risk of mortality from competing causes, PSA testing is unlikely to provide benefit. ${ }^{45}$ The CUA recognizes that estimating life expectancy is challenging. ${ }^{46}$ Nonetheless, it is recommended that physicians take into account a patient's general health status and competing risks of mortality when considering whether or not to offer PSA testing. If life expectancy is limited by other serious illnesses or comorbidities, PSA screening should not be initiated or can be discontinued.

\section{Adjunctive strategies for improving prostate cancer early diagnosis}

The past two decades have seen the development or evaluation of several potential adjunctive measures that may increase the benefits or reduce the harms associated with screening in addition to PSA. Specifically, PSA kinetics, PSA density, percent free PSA, biomarker panels, and prostate risk calculators may help select patients at higher or lower risk of significant cancer. The refinement of prostate multiparametric magnetic resonance imaging (mpMRI) may also benefit selected individuals. Below we provide a summary of the most commonly used modalities currently available.

mpMRI

Recently, Cancer Care Ontario (CCO) published recommendations on the use of mpMRI in the initial diagnosis of prostate cancer based on a systematic review of the literature. ${ }^{47}$ The CUA endorses these guidelines and their recommendations are summarized below.

5a. In patients with an elevated risk of clinically significant prostate cancer (according to PSA levels and/ or nomograms) who are biopsy-naive, $m p M R I$ followed by targeted biopsy (biopsy directed at cancersuspicious foci detected with mpMRI) should not be considered the standard of care.

Qualifying statement: The CCO guidelines panel identified that there is limited evidence on the utility of $m p M R I$ in the biopsy-naive setting and that the studies that do exist are of poor- to moderate-quality. In addition, they found that the currently available studies indicate that that the diagnostic characteristics of mpMRI in this setting are poor to moderate (particular with regards to specificity and positive predictive value).

Since the publication of the CCO guidelines, an additional large, multicentre, prospective cohort study has been published evaluating the diagnostic utility of $\mathrm{mpMRI}$ in men at risk for prostate cancer. ${ }^{48}$ The PROMIS study compared the accuracy of mpMRI with transrectal ultrasound (TRUS) biopsy to determine the utility of mpMRI as a triage test to decide which men with an elevated PSA may be able to avoid biopsy. In total, 576 men with a clinical suspicion of prostate cancer (PSA $\leq 15 \mathrm{ng} / \mathrm{ml}$ ) underwent mpMRI followed by TRUS and template prostate mapping biopsy. Overall, mpMRI displayed a moderate sensitivity and negative predictive value for predicting Gleason $\geq 3+4$ disease $(88 \%$ and $76 \%$, respectively), but the specificity and positive predictive value were poor ( $45 \%$ and $65 \%$, respectively). Overall, we believe that the results of this study do not modify the conclusions of the $\mathrm{CCO}$, and the CUA guidelines committee agrees with the recommendation that $\mathrm{mpMRI}$ should not be routinely used in the biopsy-naive setting.

$5 b$. In men who had a prior negative TRUS-guided systematic biopsy who demonstrate an increasing risk of having clinically significant prostate cancer since prior biopsy (e.g., continued rise in PSA and/ or change in findings from digital rectal examination [DRE]), mpMRI followed by targeted biopsy may be considered to help in detecting more clinically significant prostate cancer patients compared with repeated TRUS-guided systematic biopsy.

Qualifying statement: The CCO guidelines panel identified that patients with a prior negative TRUS-guided systematic 
biopsy who demonstrate increasing risk of clinically significant prostate cancer may benefit from undergoing mpMRI prior to repeat biopsy. Although the quality of evidence again ranged from poor to moderate, a persistent trend emerged showing that mpMRI followed by targeted biopsy detects a higher number of clinically significant prostate cancers relative to repeat systematic TRUS biopsy alone. Thus, we agree with the CCO that mpMRI can be considered prior to undergoing repeat prostate biopsy; however, the CUA acknowledges that there may be practical limitations to this approach, such as timely access to MRI and variations in quality and interpretation.

\section{PSA kinetics}

Annual PSA velocity (PSAV) or PSA doubling time (PSADT) can be established from serial measurements of PSA over time. Historical reports have identified that a PSAV greater than $0.75 \mathrm{ng} / \mathrm{ml} /$ year may indicate an increased risk of prostate cancer. ${ }^{49}$ Additionally, data from longitudinal studies have illustrated that PSAV greater than $0.35 \mathrm{ng} / \mathrm{ml} /$ year (when total PSA is $<4.0 \mathrm{ng} / \mathrm{ml}$ ) is associated with a higher relative risk of prostate cancer death, ${ }^{50}$ suggesting that PSAV can be used as potential prognostic marker for aggressive disease; however, other studies, including a large systematic review of 64 articles, identified that there is conflicting evidence on the incremental value of PSAV over absolute PSA level alone..$^{51-53}$ It is clear that a sustained and substantial rise in PSA over time is a concerning finding and warrants investigation. Furthermore, a stable or declining PSA is reassuring in men with PSA levels that slightly exceed PSA thresholds. The CUA does not recommend using PSAV alone for clinical decision-making in men undergoing routine screening; however, PSAV can provide additional information about a patient's risk of prostate cancer.

\section{PSA density}

PSA density (PSAD) is the serum PSA divided by prostate volume. A PSAD threshold of $>0.15 \mathrm{ng} / \mathrm{ml}^{\prime} \mathrm{cm}^{3}$ has been suggested to distinguish men at risk from prostate cancer, and studies have also linked higher PSAD with adverse pathological features at the time of prostatectomy; ${ }^{54,55}$ however, others have failed to validate these findings. ${ }^{56,57}$ Substantial inter-observer variability from the estimation of prostate volume on ultrasound also raises further questions regarding the reliability of PSAD. ${ }^{58,59}$ Due to the lack of empirical validation, the use of PSAD alone for clinical decision-making is discouraged; however, use of PSAD can be considered adjunctively in men with known prostate volumes.

\section{Percent free PSA}

The measurement of percent free PSA has been studied as a risk-stratifying tool aimed at distinguishing men at risk from prostate cancer vs. those with elevations in PSA from benign causes. Several studies have illustrated the potential utility of percent free PSA for identifying men with disease. ${ }^{60-64}$ In a large, multicentre, prospective study, prostate cancer (all grades) was detected in $56 \%$ of men with a free-to-total PSA ratio of less than 0.10 (for men with a PSA between 4 and $10 \mathrm{ng} / \mathrm{ml}$ ), whereas cancer was detected in $8 \%$ of men with a ratio greater than $0.25 .^{65}$ In a recent publication, a total of 6982 percent free and total PSA measurements were obtained over a 12-year time span from a single institution. Percent free PSA used as a reflex marker demonstrated high levels of performance, with the capability of sparing $66 \%$ of unnecessary prostate biopsies. ${ }^{66}$ Additionally, it was identified that similar to PSA, percent free PSA can also fluctuate, therefore stressing the need for repeat confirmatory testing prior to clinical decision-making. The use of percent free PSA alone for clinical decision-making is not recommended; however, percent free PSA can be useful in estimating the risk of underlying disease in men with elevations in PSA (Level of evidence: 2; Grade of recommendation : C).

\section{Biomarkers}

\section{Four-kallikrein panel (4Kscore $\left.{ }^{\circledR}\right)$}

The four-kallikrein panel, or 4Kscore is a commercially available test combining total PSA, free PSA, intact PSA, and human kallikrein 2 with age, DRE results, and prior biopsy status in order to generate a risk estimate of harbouring Gleason $\geq 7$ disease. Originally developed using data from the ERSPC and the Prostate Testing for Cancer and Treatment (ProtecT) studies, ${ }^{67-69}$ there is evidence of clinical utility over PSA alone for predicting the presence of high-grade prostate cancer. The test has been validated in several subsequent studies evaluating previously screened men, unscreened men, and men with a prior negative biopsy ${ }^{67,68,70-73}$ (area under the curve $[\mathrm{AUC}]$ of 0.71-0.82). The 4 Kscore was also validated in a large, prospective study of 1012 men from 26 different centres in the U.S. ${ }^{74}$ The 4 Kscore demonstrated a better discrimination in predicting Gleason $\geq 7$ cancer compared to the modified Prostate Cancer Prevention Trial Risk Calculator 2.0 model (AUC 0.82 vs. $0.74 ; \mathrm{p}<0.0001$ ).

The potential clinical impact of the $4 \mathrm{~K}$ on biopsy decisionmaking has also been assessed. The test influenced biopsy decision-making in $89 \%$ of men and reduced biopsies by $65 \%$ in 611 men that were evaluated by both academic and community urologists. ${ }^{75}$ Originally developed for use in men with a PSA $<10 \mathrm{ng} / \mathrm{ml}$, its use has also been extended and validated in men with a PSA up to $25 \mathrm{ng} / \mathrm{ml}^{76}$ 


\section{Prostate Health Index $\left(\mathrm{PH}{ }^{\circledR}\right)$}

The Prostate Health Index (PHI) is a commercially available test derived from PSA and its isoforms (total PSA, free PSA, and [-2] pro PSA) originally developed to estimate the risk of harbouring Gleason 7 or greater disease in men with a PSA between 2 and $10 \mathrm{ng} / \mathrm{ml} .{ }^{77}$ Use of the test was initially validated in a multi-institutional, prospective trial evaluating 892 men for the presence of Gleason $\geq 4+3$ prostate cancer, which found that $\mathrm{PHI}$ could improve the discrimination of patients with or without clinically significant disease compared with PSA and free-to-total PSA (AUC 0.72 vs. 0.67). ${ }^{78}$ Subsequent validation studies have confirmed this finding, showing that PHI can outperform total and percent free PSA in predicting high-risk disease, including in biopsy-naive men. ${ }^{79,80}$ Additionally, in a large, multicentre, prospective study, PHI significantly improved the performance of the PCPT and ERSPC risk calculators (see below) in men with a PSA between 2 and $10 \mathrm{ng} / \mathrm{ml}$ for predicting the risk of Gleason $\geq 7$ prostate cancer. ${ }^{81}$ A multicentre cohort study evaluating the clinical utility of $\mathrm{PHI}$ found that it reduced unnecessary biopsies by $36 \%$ and only missed $2.5 \%$ of highgrade cancers. ${ }^{80}$

When comparing $\mathrm{PHI}$ and the $4 \mathrm{~K}$ score, the two tests appear to demonstrate similar discriminatory ability in predicting high-risk prostate cancer in men with a PSA between 3 and $15 \mathrm{ng} / \mathrm{ml}$ (AUC 4Kscore 0.718 vs. PHI 0.711). ${ }^{82}$

\section{Prostate cancer antigen $3(P C A 3)$ score}

Prostate cancer antigen 3 (PCA3) is a non-coding RNA gene that is only expressed in the prostate and is overexpressed in prostate cancer. Unlike the 4Kscore and PHI, which are based on serum measurements, PCA3 is measured from a urine sample that is obtained after DRE.

Multiple studies evaluating the PCA3 in men undergoing repeat biopsy have demonstrated an improved diagnostic accuracy for prostate cancer detection relative to PSA alone. ${ }^{83-86}$ In a multicentre, prospective study of 466 men with a history of a negative biopsy, those with a score of less than 25 were almost five times more likely to have a negative repeat biopsy compared to those with a score $\geq 25 ;{ }^{86}$ however, the role of PCA3 in men with no history of a prior biopsy is uncertain. In a prospective validation study conducted by the National Cancer Institute, the performance of PCA3 was assessed in 859 men that were enrolled from 11 centres. $^{87}$ In the biopsy-naive setting, there was a high rate of undiagnosed high-grade cancers (13\%) using a PCA3 score $<20$, compared to $3 \%$ in the repeat setting. ${ }^{87}$

In men with a moderately elevated PSA, the 4Kscore, PHI, and PCA3 may improve the prediction of clinically significant prostate cancer and provide additional information over PSA alone; however, the CUA recognizes that these are expensive tests that are not currently publicly funded in Canada. At the present time, based upon the available data, the CUA does not encourage the widespread use of these tests.

\section{Prostate risk calculators}

Several prostate cancer risk nomograms have been developed to aid in the detection of clinically significant prostate cancer. ${ }^{88}$ One well-performed systematic review and metaanalysis has examined the diagnostic accuracy of multiple prostate cancer risk nomograms; ${ }^{88}$ however, most of the available nomograms remained untested or inadequately validated. In the six nomograms with adequate validation across several study populations, the discrimination properties for prostate cancer detection were moderate (AUC 0.66-0.79) and most did not assess calibration. ${ }^{88}$ In addition, most nomograms were not validated for the prediction of clinically significant disease.

Currently, the most widely used calculators for the prediction of clinically significant disease include the PCPT prostate cancer risk calculator (PCPT-RC) ${ }^{89,90}$ and the ERSPC prostate cancer risk calculator (ERSPC-RC). ${ }^{91}$ The PCPT-RC uses clinical factors, including age, PSA level, ethnic background, family history, DRE results, and prior biopsy results in order to estimate the risk of both low-risk and high-risk (biopsy Gleason 27 ) prostate cancer, separately. Similarly, the ERSPC-RC uses PSA level, DRE results, prior biopsy results, prostate volume, and TRUS findings in order to determine the risk of both any prostate cancer and clinically significant prostate cancer (pT stage $>\mathrm{T} 2 \mathrm{~b}$ and/or biopsy Gleason 27 ). In addition, there is a prostate risk calculator that was developed using data from Canadian men. ${ }^{92}$ This calculator uses PSA level, free-to-total PSA, age, voiding symptoms, ethnicity, family history, and DRE results in order to estimate the risk of both any prostate cancer and high-risk (Gleason $\geq 7$ ) prostate cancer. Although all of these calculators can be used to estimate the risk of harbouring clinically significant prostate cancer prior to prostate biopsy, they again display only moderate predictive accuracy, which varies across different study populations. ${ }^{88,93-96}$ Nonetheless, their online availability, ease of use, and improvement upon PSA alone make them attractive adjuncts when counselling patients considering undergoing prostate biopsy. Thus, prostate risk calculators can be used to estimate the risk of clinically significant prostate cancer in men presenting with an elevated PSA.

\section{Prostate biopsy decision-making}

Determining the threshold for performing a prostate biopsy should be an individualized process. Although various single PSA thresholds, as well as age- ${ }^{97-99}$ and race-specific ${ }^{97,100}$ PSA thresholds have been proposed for biopsy decision-making, no uniform cutoff for PSA can be recommended for all men. 
Additionally, a single PSA measurement should not be used to guide biopsy decision-making. Numerous studies have documented the measured changes and fluctuations in PSA levels over time. ${ }^{101,102}$ In a Canadian study that evaluated over 1000 men with elevated PSA ( $>4 \mathrm{ng} / \mathrm{ml}$ ), it was demonstrated that by repeating PSA testing, 25\% of the cohort had resolution to low levels that did not require further investigation. ${ }^{102}$ For these reasons, it is recommended that PSA should be repeated and confirmed before proceeding to prostate biopsy.

The decision to proceed with prostate biopsy should take into account several factors, including PSA level, results from adjunct tests or risk calculators, competing comorbidities, and patient preferences. In addition, a suspicious finding on DRE may warrant consideration of prostate biopsy in healthy men. Although the added utility of DRE in addition to PSA is controversial, DRE may increase the detection of clinically significant disease $\mathrm{e}^{103-105}$ and men undergoing prostate cancer screening should have DRE performed at the same interval as PSA testing.

The CUA acknowledges that the implementation of a successful screening program must also consider individual variations in patient preferences. Men undergoing screening should be involved in the decision-making regarding prostate biopsy. The decision to pursue biopsy should be based upon a discussion of the best evidence for estimating the risk for aggressive prostate cancer (Expert opinion).

\section{Conclusion}

Population-based screening has demonstrated benefits in reducing prostate cancer mortality; however, decisions to proceed with screening should be based upon shared decision-making, recognizing that each patient has a different perspective with regards to the potential benefits and harms of prostate cancer screening and treatment. These recommendations summarize the best available evidence for conducting prostate cancer screening in a Canadian context, with an emphasis placed on maximizing the detection of aggressive and potentially lethal disease and minimizing the harms associated with unnecessary prostate biopsy and discovery of clinically insignificant prostate cancer. We hope that these recommendations will help promote initiatives for improving the health of Canadian men.

Competing interests: The authors report no competing personal or financial interests.

This paper has been peer-reviewed.

\section{References}

1. Canadian Cancer Statistics 2015. Canadian Cancer Society. 2015.

2. Abrams $P$, Khoury $S$. International Consultation on Urological Diseases: Evidence-based medicine overview of the main steps for developing and grading guideline recommendations. Neurourol Urodyn 2010;29:116-8. https://doi.org/10.1002/nau.20845

3. Carter $\mathrm{HB}$, Albertsen PC, Barry MJ, et al. Early detection of prostate cancer: AUA guideline. J Urol 2013;190:419-26. https://doi.org/10.1016/i.juro.2013.04.119

4. National Comprehensive Cancer Network. Prostate Cancer Early Detection, Version 2.2016; April 28, 2016. Available at htrps://www.nccn.org/professionals/physician_gls/pdf/prostate_detection.pdf. Accessed May 9, 2017.

5. Mottet N, Bellmunt J, Bolla M, et al. EAU-ESTRO-SIOG guidelines on prostate cancer. Part 1 : Screening, diagnosis, and local treatment with curative intent. Eur Urol 2017;71:618-29. https://doi.org/10.1016/i. eururo.2016.08.003

6. Qaseem A, Barry MJ, Denberg TD, et al. Screening for prostate cancer: A guidance statement from the Clinical Guidelines Committee of the American College of Physicians. Annals Int Med 2013;158:761-9. https://doi.org/10.7326/0003-4819-158-10-201305210-00633

7. United States Preventative Services Task Force. Draft recommendation statement on prostate cancer screening. Available at https://www.uspreventiveservicestaskforce.org/Page/Document/ RecommendationStatementDraft/prostate-cancer-screeningl. Accessed May 9, 2017.

8. Bell N, Connor Gorber S, Shane A, et al. Recommendations on screening for prostate cancer with the prostate-specific antigen test. Can Med Assoc J 2014;186:1225-34. https://doi.org/10.1503/ cmaj. 140703

9. Andriole GL, Crawford ED, Grubb RL 3rd, et al. Mortality results from a randomized prostate-cancer screening trial. N Eng J Med 2009;360:1310-9. https://doi.org/10.1056/NEJMoa0810696

10. Schroder FH, Hugosson J, Roobol MJ, et al. Screening and prostate-cancer mortality in a randomized European study. N Eng J Med 2009;360:1320-8. https://doi.org/10.1056/NEJMoa0810084

11. Hugosson J, Carlsson S, Aus G, et al. Mortality results from the Goteborg randomized, population-based prostate-cancer screening trial. Lancet Oncol 2010;11:725-32. https://doi.org/10.1016/S1470$2045(10) 70146-7$

12. Kiellman A, Akre 0, Norming U, et al. 15-year followup of a population-based prostate cancer screening study. J Urol 2009;181:1615-21; discussion 21. https://doi.org/10.1016/i.juro.2008.11.115

13. Labrie F, Candas B, Cusan L, et al. Screening decreases prostate cancer mortality: 11-year followup of the 1988 Quebec prospective, randomized, controlled trial. Prostate 2004;59:311-8. https://doi.org/10.1002/pros.20017

14. Sandblom G, Varenhorst E, Rosell J, et al. Randomized prostate cancer screening trial: 20-year followup. BMJ 2011;342:d1539. https://doi.org/10.1136/bmi.d1539

15. Pinsky PF, Prorok PC, Yu K, et al. Extended mortality results for prostate cancer screening in the PLCO trial with median followup of 15 years. Cancer 2017;123:592-9. https://doi.org/10.1002/cncr.30474

16. Schroder FH, Hugosson J, Roobol MJ, et al. Screening and prostate cancer mortality: Results of the European Randomized Study of Screening for Prostate Cancer (ERSPC) at 13 years of followup. Lancet 2014;384:2027-35. https://doi.org/10.1016/S0140-6736(14)60525-0

17. Arnsrud Godtman R, Holmberg E, Lilja H, et al. Opportunistic testing vs. organized prostate-specific antigen screening: Outcome after 18 years in the Goteborg randomized, population-based prostate cancer screening trial. Eur Urol 2015;68:354-60. https://doi.org/10.1016/i.eururo.2014.12.006

18. Otto SJ, van der Cruijsen IW, Liem MK, et al. Effective PSA contamination in the Rotterdam section of the European Randomized Study of Screening for Prostate Cancer. Int I Cancer 2003;105:394-9. https://doi.org/10.1002/ijc.11074

19. Lujan $M$, Paez A, Pascual $C$, et al. Extent of prostate-specific antigen contamination in the Spanish section of the European Randomized Study of Screening for Prostate Cancer (ERSPC). Eur Urol 2006;50:1234-40; discussion 9-40. htrps://doi.org/10.1016/i.eururo.2006.04.015

20. Turner EL, Metcalfe C, Donovan JL, et al. Design and preliminary recruitment results of the Cluster randomized trial of PSA testing for Prostate cancer (CAP). Br J Cancer 2014;110:2829-36. hitps://doi.org/10.1038/bic.2014.242

21. Bartsch G, Horninger W, Klocker H, et al. Prostate cancer mortality after introduction of prostatespecific antigen mass screening in the Federal State of Tyrol, Austria. Urology 2001;58:417-24. https://doi.org/10.1016/S0090-4295(01)01264-X

22. Roberts RO, Bergstralh EJ, Katusic SK, et al. Decline in prostate cancer mortality from 1980 to 1997, and an update on incidence trends in Olmsted County, Minnesota. J Urol 1999;161:529-33. https://doi.org/10.1016/S0022-5347(01)61941-4

23. Collin SM, Martin RM, Metcalfe C, et al. Prostate-cancer mortality in the USA and UK in 1975-2004: An ecological study. Lancet Oncol 2008;9:445-52. https://doi.org/10.1016/S1470-2045(08)70104-9 
24. Oliver SE, Gunnell D, Donovan JL. Comparison of trends in prostate-cancer mortality in England and Wales and the USA. Lancet 2000;355:1788-9. https://doi.org/10.1016/S0140-6736(00)02269-8

25. Etzioni R, Tsodikov A, Mariotto A, et al. Quantifying the role of PSA screening in the US prostate cancer mortality decline. Cancer Causes Control 2008;19:175-81. https://doi.org/10.1007/s10552-007-9083-8

26. Gulati R, Gore JL, Etzioni R. Comparative effectiveness of alternative prostate-specific antigen-based prostate cancer screening strategies: Model estimates of potential benefits and harms. Annals Int Med 2013;158:145-53. https://doi.org/10.7326/0003-4819-158-3-201302050-00003

27. Heïnsdijk EA, Wever EM, Auvinen $A$, et al. Quality-of-life effects of prostate-specific antigen screening. $N$ Eng J Med 2012;367:595-605. https://doi.org/10.1056/NEJMoal 201637

28. Bhindi B, Mamdani M, Kulkarni GS, et al. Impact of the U.S. Preventive Services Task Force recommendations against prostate-specific antigen screening on prostate biopsy and cancer detection rates. I Urol 2015;193:1519-24. https://doi.org/10.1016/i.juro.2014.11.096

29. Barocas DA, Mallin K, Graves AJ, et al. Effect of the USPSTF Grade D recommendation against screening for prostate cancer on incident prostate cancer diagnoses in the United States. J Urol 2015;194:1587-93. https://doi.org/10.1016/i.juro.2015.06.075

30. Hoffman RM, Meisner AL, Arap W, et al. Trends in United States prostate cancer incidence rates by age and stage, 1995-2012. Cancer Epidemiol Biomarkers Prev 2016;25:259-63. https://doi.org/10.1158/1055-9965.EPl-15-0723

31. Hu JC, Nguyen P, Mao J, et al. Increase in prostate cancer distant metastases at diagnosis in the United States. JAMA Oncol 2017;3:705-7. https://doi.org/10.1001/jamaoncol.2016.5465

32. Epstein JI, Walsh PC, Carmichael M, et al. Pathological and clinical findings to predict tumor extent of nonpalpable (stage Tlc) prostate cancer. JAMA 1994;271:368-74. https://doi.org/10.1001/ jama.1994.03510290050036

33. Etzioni R, Penson DF, Legler JM, et al. Overdiagnosis due to prostate-specific antigen screening: Lessons from U.S. prostate cancer incidence trends. J Nat Canc Inst 2002;94:981-90. https://doi.org/10.1093/ inci/94.13.981

34. Draisma G, Boer R, Otto SJ, et al. Lead times and overdetection due to prostate-specific antigen screening: Estimates from the European Randomized Study of Screening for Prostate Cancer. J Nat Canc Inst 2003;95:868-78. https://doi.org/10.1093/inci/95.12.868

35. Loeb S, Biurlin MA, Nicholson J, et al. Overdiagnosis and overtreatment of prostate cancer. Eur Urol 2014;65:1046-55. htrps://doi.org/10.1016/i.eururo.2013.12.062

36. Wever EM, Draisma G, Heijnsdijk EA, et al. Prostate-specific antigen screening in the United States vs. in the European Randomized Study of Screening for Prostate Cancer-Rotterdam. J Nat Canc Inst 2010;102:352-5. https://doi.org/10.1093/inci/dip533

37. Latini DM, Hart SL, Knight SJ, et al. The relationship between anxiety and time to treatment for patients with prostate cancer on surveillance. J Urol 2007;178:826-31. htrps://doi.org/10.1016/i. juro.2007.05.039

38. Albright $F$, Stephenson RA, Agarwal N, et al. Prostate cancer risk prediction based on complete prostate cancer family history. Prostate 2015;75:390-8. https://doi.org/10.1002/pros.22925

39. Preston MA, Batista JL, Wilson KM, et al. Baseline prostate-specific antigen levels in midlife predict lethal prostate cancer. J Clin Oncol 2016;34:2705-11. https://doi.org/10.1200/JC0.2016.66.7527

40. Gelfond J, Choate K, Ankerst DP, et al. Intermediate-term risk of prostate cancer is directly related to baseline prostate-specific antigen: Implications for reducing the burden of prostate-specific antigen screening. J Urol 2015;194:46-51. https://doi.org/10.1016/i.juro.2015.02.043

41. Vickers AJ, Ulmert D, Sjoberg DD, et al. Strategy for detection of prostate cancer based on relation between prostate-specific antigen at age 40-55 and long-term risk of metastasis: Case-control study. BMJ 2013;346:f2023. https://doi.org/10.1136/bmi.f2023

42. Carlsson S, Assel M, Sjoberg D, et al. Influence of blood prostate-specific antigen levels at age 60 on benefits and harms of prostate cancer screening: Population-based cohort study. BMJ 2014;348:g2296. https://doi.org/10.1136/bmi.g2296

43. Vickers AJ, Cronin AM, Bjork T, et al. Prostate-specific antigen concentration at age 60 and death or metastasis from prostate cancer: Case-control study. BMJ 2010;341:c4521. https://doi.org/10.1136/ bmi.c4521

44. Vickers AJ, Sjoberg DD, Ulmert D, et al. Empirical estimates of prostate cancer overdiagnosis by age and prostate-specific antigen. BMC Med 2014;12:26. https://doi.org/10.1186/1741-7015-12-26

45. Hamdy FC, Donovan JL, Lane JA, et al. 10-year outcomes after monitoring, surgery, or radiotherapy for localized prostate cancer. N Eng J Medicine 2016;375:1415-24. https://doi.org/10.1056/ NEJMoal 606220

46. Sammon JD, Abdollah F, D'Amico A, et al. Predicting life expectancy in men diagnosed with prostate cancer. Eur Urol 2015;68:756-65. https://doi.org/10.1016/j.eururo.2015.03.020

47. Haider $M A$, Yao $X$, Loblaw $A$, et al. Evidence-based guideline recommendations on multiparametric magnetic resonance imaging in the diagnosis of prostate cancer: A Cancer Care Ontario clinical practice guideline. Can Urol Assoc J 2017;11:E1-7. https://doi.org/10.5489/cuai.3968
48. Ahmed HU, El-Shater Bosaily A, Brown LC, et al. Diagnostic accuracy of multiparametric MRI and TRUS biopsy in prostate cancer (PROMIS): A paired validating confirmatory study. Lancet 2017;389:815-22. https://doi.org/10.1016/S0140-6736(16)32401-1

49. Carter HB, Pearson JD, Metter EJ, et al. Longitudinal evaluation of prostate-specific antigen levels in men with and without prostate disease. JAMA 1992;267:2215-20. https://doi.org/10.1001/ jama.1992.03480160073037

50. Carter HB, Ferrucci L, Kettermann A, et al. Detection of life-threatening prostate cancer with prostate-specific antigen velocity during a window of curability. J Nat Canc Inst 2006;98:1521-7. h Hps://doi.org/10.1093/inci/dij410

51. O'Brien MF, Cronin AM, Fearn PA, et al. Pretreatment prostate-specific antigen (PSA) velocity and doubling time are associated with outcome but neither improves prediction of outcome beyond pretreatment PSA alone in patients treated with radical prostatectomy. J Clin Oncol 2009;27:3591-7. https://doi.org/10.1200/JC0.2008.19.9794

52. Vickers AJ, Savage $C, O^{\prime} B r i e n ~ M F$, et al. Systematic review of pretreatment prostate-specific antigen velocity and doubling time as predictors for prostate cancer. J Clin Oncol 2009;27:398-403. https://doi.org/10.1200/JC0.2008.18.1685

53. Roobol MJ, Kranse R, de Koning HJ, et al. Prostate-specific antigen velocity at low prostate-specific antigen levels as screening tool for prostate cancer: Results of second screening round of ERSPC (ROTTERDAM). Urology 2004;63:309-13; discussion 13-5. https://doi.org/10.1016/i.urology.2003.09.083

54. Allan RW, Sanderson H, Epstein Jl. Correlation of minute (0.5 MM or less) focus of prostate adenocarcinoma on needle biopsy with radical prostatectomy specimen: Role of prostate-specific antigen density. J Urol 2003;170:370-2. https://doi.org/10.1097/01.ju.0000074747.72993.cb

55. Radwan MH, Yan Y, Luly JR, et al. Prostate-specific antigen density predicts adverse pathology and increased risk of biochemical failure. Urology 2007;69:1121-7. https://doi.org/10.1016/i.urology.2007.01.087

56. Lujan $M$, Paez A, Llanes $L$, et al. Prostate-specific antigen density. Is there a role for this parameter when screening for prostate cancer? Prostate Cancer Prostatic Dis 2001;4:146-9. https://doi.org/10.1038/ si.pcan. 4500509

57. Djavan B, Remzi M, Zlotta AR, et al. Complexed prostate-specific antigen, complexed prostate-specific antigen density of total and transition zone, complexed/total prostate-specific antigen ratio, free-to-total prostate-specific antigen ratio, density of total and transition zone prostate-specific antigen: Results of the prospective multicentre European trial. Urology 2002;60:4-9. https://doi.org/10.1016/S00904295(02)01896-4

58. Augustin H, Graefen M, Palisaar J, et al. Prognostic significance of visible lesions on transrectal ultrasound in impalpable prostate cancers: Implications for staging. J Clin Oncol 2003;21:2860-8. https://doi.org/10.1200/JC0.2003.11.130

59. Resnick MI, Smith JA Jr, Scardino PT, et al. Transrectal prostate ultrasonography: Variability of interpretation. J Urol 1997;158:856-60. https://doi.org/10.1016/S0022-5347(01)64336-2

60. Etzioni R, Falcon S, Gann PH, et al. Prostate-specific antigen and free prostate-specific antigen in the early detection of prostate cancer: Do combination tests improve detection? Cancer Epidemiology Biomarkers Prev 2004;13:1640-5.

61. Bruzzese D, Mazzarella C, Ferro M, et al. Prostate health index vs percent free prostate-specific antigen for prostate cancer detection in men with "gray" prostate-specific antigen levels at first biopsy: Systematic review and meta-analysis. Trans/ Res 2014;164:444-51. https://doi.org/10.1016/j.trsl.2014.06.006

62. Liang Y, Ankerst DP, Ketchum NS, et al. Prospective evaluation of operating characteristics of prostate cancer detection biomarkers. J Urol 2011;185:104-10. htrps://doi.org/10.1016/i.juro.2010.08.088

63. Lee R, Localio AR, Armstrong K, et al. A meta-analysis of the performance characteristics of the free prostatespecific antigen test. Urology 2006;67:762-8. https://doi.org/10.1016/i.urology.2005.10.052

64. Partin AW, Brawer MK, Subong EN, et al. Prospective evaluation of percent free-PSA and complexed-PSA for early detection of prostate cancer. Prostate Cancer Prostatic Dis 1998;1:197-203. https://doi.org/10.1038/si.pcan.4500232

65. Catalona WJ, Partin AW, Slawin KM, et al. Use of the percentage of free prostate-specific antigen to enhance differentiation of prostate cancer from benign prostatic disease: A prospective, multicentre clinical trial. JAMA 1998;279:1542-7. https://doi.org/10.1001/jama.279.19.1542

66. Ankerst DP, Gelfond J, Goros $M$, et al. Serial percent free prostate-specific antigen in combination with prostate-specific antigen for population-based early detection of prostate cancer. J Urol 2016; 196:355-60. https://doi.org/10.1016/i.juro.2016.03.011

67. Vickers AJ, Cronin AM, Aus $G$, et al. A panel of kallikrein markers can reduce unnecessary biopsy for prostate cancer: Data from the European Randomized Study of Prostate Cancer Screening in Goteborg, Sweden. BMC Med 2008;6:19. https://doi.org/10.1186/1741-7015-6-19

68. Vickers $A$, Cronin $A$, Roobol $M$, et al. Reducing unnecessary biopsy during prostate cancer screening using a four-kallikrein panel: An independent replication. J Clin Oncol 2010;28:2493-8. https://doi.org/10.1200/JC0.2009.24.1968 
69. Bryant RJ, Sioberg DD, Vickers AJ, et al. Predicting high-grade cancer at 10-core prostate biopsy using four kallikrein markers measured in blood in the ProtecT study. J Nat Canc Inst 2015;107.

70. Vickers AJ, Cronin AM, Roobol MJ, et al. A four-kallikrein panel predicts prostate cancer in men with recent screening: Data from the European Randomized Study of Screening for Prostate Cancer, Rotterdam. Clinical Cancer Research 2010;16:3232-9. https://doi.org/10.1158/1078-0432.CCR-10-0122

71. Vickers AJ, Cronin AM, Aus G, et al. Impact of recent screening on predicting the outcome of prostate cancer biopsy in men with elevated prostate-specific antigen: Data from the European Randomized Study of Prostate Cancer Screening in Gothenburg, Sweden. Cancer 2010;116:2612-20. https://doi. org/10.1002/cncr.25010

72. Benchikh A, Savage C, Cronin A, et al. A panel of kallikrein markers can predict outcome of prostate biopsy following clinical workup: An independent validation study from the European Randomized Study of Prostate Cancer screening, France. BMC Cancer 2010;10:635. https://doi.org/10.1186/1471-2407-10-635

73. Gupta A, Roobol MJ, Savage CJ, et al. A four-kallikrein panel for the prediction of repeat prostate biopsy: Data from the European Randomized Study of Prostate Cancer screening in Rotterdam, Netherlands. $\mathrm{Br}$ J Cancer 2010;103:708-14. https://doi.org/10.1038/si.bic.6605815

74. Parekh DJ, Punnen S, Sjoberg DD, et al. A multi-institutional prospective trial in the USA confirms that the 4Kscore accurately identifies men with high-grade prostate cancer. Eur Urol 2015;68:464-70. https://doi.org/10.1016/i.eururo.2014.10.021

75. Konety B, Zappala SM, Parekh DJ, et al. The 4Kscore(R) test reduces prostate biopsy rates in community and academic urology practices. Rev Urol 2015;17:231-40.

76. Vickers A, Vertosick EA, Sjoberg DD, et al. Properties of the 4-Kallikrein panel outside the diagnostic gray zone: Meta-analysis of patients with positive digital rectal examination or prostate-specific antigen $10 \mathrm{ng} /$ $\mathrm{ml}$ and above. J Urol 2017;197:607-13. https://doi.org/10.1016/i.juro.2016.09.086

77. Jansen FH, van Schaik RH, Kurstiens J, et al. Prostate-specific antigen (PSA) isoform P2PSA in combination with total PSA and free PSA improves diagnostic accuracy in prostate cancer detection. Eur Urol 2010;57:921-7. https://doi.org/10.1016/i.eururo.2010.02.003

78. Catalona WJ, Partin AW, Sanda MG, et al. A multicentre study of [-2]pro-prostate-specific antigen combined with prostate-specific antigen and free prostate-specific antigen for prostate cancer detection in the 2.0-10.0 ng/ml prostate-specific antigen range. J Urol 2011;185:1650-5. https://doi.org/10.1016/i juro.2010.12.032

79. Loeb S, Sanda MG, Broyles DL, et al. The Prostate Health Index selectively identifies clinically significant prostate cancer. J Urol 2015;193:1163-9. https://doi.org/10.1016/i.juro.2014.10.121

80. de la Calle C, Patil D, Wei JT, et al. Multicentre evaluation of the Prostate Health Index to detect aggressive prostate cancer in biopsy-naive men. J Urol 2015;194:65-72. htrps://doi.org/10.1016/i juro.2015.01.091

81. Loeb S, Shin SS, Broyles DL, et al. Prostate Health Index improves multivariable risk prediction of aggressive prostate cancer. BJU Int 2017;12:61-8. https://doi.org/10.1111/bju.13676

82. Nordstrom T, Vickers A, Assel M, et al. Comparison between the four-kallikrein panel and Prostate Health Index for predicting prostate cancer. Eur Urol 2015;68:139-46. https://doi.org/10.1016/i. eururo.2014.08.010

83. Aubin SM, Reid J, Sarno MJ, et al. PCA3 molecular urine test for predicting repeat prostate biopsy outcome in populations at risk: Validation in the placebo arm of the dutasteride REDUCE trial. J Urol 2010;184:1947-52. https://doi.org/10.1016/i.juro.2010.06.098

84. Auprich M, Bjartell A, Chun FK, et al. Contemporary role of prostate cancer antigen 3 in the management of prostate cancer. Eur Urol 2011;60:1045-54. hittps://doi.org/10.1016/i.eururo.2011.08.003

85. Bradley LA, Palomaki GE, Gutman S, et al. Comparative effectiveness review: Prostate cancer antigen 3 testing for the diagnosis and management of prostate cancer. J Urol 2013;190:389-98. https://doi.org/10.1016/i.juro.2013.02.005

86. Gittelman MC, Hertzman B, Bailen J, et al. PCA3 molecular urine test as a predictor of repeat prostate biopsy outcome in men with previous negative biopsies: A prospective, multicentre clinical study. J Urol 2013;190:64-9. https://doi.org/10.1016/i.juro.2013.02.018

87. Wei JT, Feng Z, Partin AW, et al. Can urinary PCA3 supplement PSA in the early detection of prostate cancer? J Clin Oncol 2014;32:4066-72. https://doi.org/10.1200/JC0.2013.52.8505

88. Lovie KS, Seigneurin A, Cathcart $P$, et al. Do prostate cancer risk models improve the predictive accuracy of PSA screening? A meta-analysis. Annals Oncol 2015;26:848-64. https://doi.org/10.1093/annonc/ mdu525

89. Ankerst DP, Hoefler J, Bock S, et al. Prostate Cancer Prevention Trial risk calculator 2.0 for the prediction of low- vs. high-grade prostate cancer. Urology 2014;83:1362-7. https://doi.org/10.1016/i. urology.2014.02.035

90. Thompson IM, Ankerst DP, Chi C, et al. Assessing prostate cancer risk: Results from the Prostate Cancer Prevention Trial. J Nat Canc Inst 2006;98:529-34. https://doi.org/10.1093/inci/dij131
91. Roobol MJ, Steyerberg EW, Kranse R, et al. A risk-based strategy improves prostate-specific antigen-driven detection of prostate cancer. Eur Urol 2010;57:79-85. https://doi.org/10.1016/i.eururo.2009.08.025

92. Nam RK, Toi A, Klotz LH, et al. Assessing individual risk for prostate cancer. J Clin Oncol 2007;25:3582-8. https://doi.org/10.1200/JC0.2007.10.6450

93. Poyet $C$, Nieboer $D$, Bhindi $B$, et al. Prostate cancer risk prediction using the novel versions of the European Randomized Study for Screening of Prostate Cancer (ERSPC) and Prostate Cancer Prevention Trial (PCPT) risk calculators: Independent validation and comparison in a contemporary European cohort. BJU Int 2016;117:401-8. https://doi.org/10.1111/bju.13314

94. Trottier G, Roobol MJ, Lawrentschuk N, et al. Comparison of risk calculators from the Prostate Cancer Prevention Trial and the European Randomized Study of Screening for Prostate Cancer in a contemporary Canadian cohort. BJU Int 2011;108:E237-44. https://doi.org/10.1111/j.1464-410X.2011.10207.x

95. Foley RW, Maweni RM, Gorman L, et al. European Randomized Study of Screening for Prostate Cancer (ERSPC) risk calculators significantly outperform the Prostate Cancer Prevention Trial (PCPT) 2.0 in the prediction of prostate cancer: A multi-institutional study. BJU Int 2016;118:706-13. https://doi.org/10.1111/bju.13437

96. Nam RK, Kattan MW, Chin JL, et al. Prospective multi-institutional study evaluating the performance of prostate cancer risk calculators. J Clin Oncol 2011;29:2959-64. https://doi.org/10.1200/ JC0.2010.32.6371

97. Oesterling JE, Jacobsen SJ, Chute CG, et al. Serum prostate-specific antigen in a community-based population of healthy men. Establishment of age-specific reference ranges. JAMA 1993;270:860-4. https:// doi.org/10.1001/jama.1993.03510070082041

98. DeAntoni EP, Crawford ED, Oesterling JE, et al. Age- and race-specific reference ranges for prostate-specific antigen from a large community-based study. Urology 1996;48:234-9. https://doi.org/10.1016/ S0090-4295(96)00091-X

99. Dalkin BL, Ahmann FR, Kopp JB. Prostate-specific antigen levels in men older than 50 years without clinical evidence of prostatic carcinoma. J Urol 1993;150:1837-9. https://doi.org/10.1016/S0022$5347(17) 35910-4$

100. Morgan TO, Jacobsen SJ, McCarthy WF, et al. Age-specific reference ranges for serum prostate-specific antigen in black men. N Eng J Med 1996;335:304-10. https://doi.org/10.1056/NEJM199608013350502

101. Eastham JA, Riedel E, Scardino PT, et al. Variation of serum prostate-specific antigen levels: An evaluation of year-to-year fluctuations. JAMA 2003;289:2695-700. https://doi.org/10.1001/jama.289.20.2695

102. Lavallee LT, Binette A, Witiuk K, et al. Reducing the harm of prostate cancer screening: Repeated prostate-specific antigen testing. Mayo Clinic Proc 2016;91:17-22. https://doi.org/10.1016/i. mayocp.2015.07.030

103. Okotie $0 T$, Roehl $K A$, Han $M$, et al. Characteristics of prostate cancer detected by digital rectal examination only. Urology 2007;70:1117-20. https://doi.org/10.1016/i.urology.2007.07.019

104. Carvalhal GF, Smith DS, Mager DE, et al. Digital rectal examination for detecting prostate cancer at prostate-specific antigen levels of $4 \mathrm{ng} / \mathrm{ml}$ or less. J Urol 1999;161:835-9. https://doi.org/10.1016/ S0022-5347(01)61785-3

105. Gosselaar C, Roobol MJ, Roemeling S, et al. Screening for prostate cancer at low PSA range: The impact of digital rectal examination on tumour incidence and tumour characteristics. Prostate 2007;67:154-61. https://doi.org/10.1002/pros.20501

Correspondence: Dr. Ricardo A. Rendon, Dalhousie University and QEEll Health Sciences Centre, Halifax, NS, Canada; rrendon@dal.ca

\begin{tabular}{l}
\hline $\begin{array}{l}\text { Appendix 1. Search string relating to prostate-specific } \\
\text { antigen screening }\end{array}$ \\
\hline - Terms: (prostate AND (cancer OR carcinoma OR tumor OR \\
tumour OR malignan*)) AND (PSA OR " Prostate-specific \\
antigen" ") AND (Screening OR Detection OR diagnosis) \\
- Filters: Clinical Study, Clinical Trial, Comparative Study, \\
Controlled Clinical Trial, Meta-Analysis, Multicenter Study, \\
Observational Study, Pragmatic Clinical Trial \\
- Filter: Since 2016 \\
- Date of search: February 2, 2017 \\
- Databases: PubMED and MEDLINE without PubMED filters \\
\hline
\end{tabular}


Rendon et al

Supplementary Table 1. Prostate cancer screening guidelines by other organizations

\section{Association}

(year)

\section{Screening}

Age (years) recommended (yes/no)
Additional details on recommendations
Frequency

- Clinicians should inform men about the potential benefits and harms of PSA-based screening for prostate cancer

- The decision about whether to be screened for prostate cancer should be an individual one NR

- Current evidence does not support separate, specific recommendations on PSA-based screening for high-risk populations $^{c}$

United States
Preventative $55-69$

Yes $^{\mathrm{b}}$

- USPSTF recommends against PSA-based screening for prostate cancer in men age 70 years and older

Task Force

(Recommendation

Statement) $)^{\mathrm{a}}$ $(2017)^{7}$

- Evidence from randomized clinical trials is consistent with no mortality benefit of PSA-based screening for prostate cancer in men age 70 years and older

$>50$

$\begin{array}{ll}\text { European } & >45 \text { if at } \\ \text { Association of } & \begin{array}{c}\text { elevated } \\ \text { risk }^{\text {c,d }}\end{array}\end{array}$

- Do not subject men to PSA testing without counselling them on the potential risks and benefits

- Offer an individualized, risk-adapted strategy for early detection to a well-informed man with a good performance status and a life-expectancy of at least 10-15 years

- Decide on the age at which early diagnosis of prostate cancer should be stopped based on life expectancy and performance status

- Randomized data suggest that men who have a life expectancy of $<15$ years are unlikely to benefit
- Baseline evaluation should include history and physical exam, including family history, medications, history of prostate disease and screening ${ }^{\mathrm{e}}$, race $^{\mathrm{f}}$ and family history of BRCA $1 / 2$ mutations

- Risk assessment should include initiating discussion of risks and benefits of prostate screening, baseline PSA ${ }^{9}$ and consideration of baseline $\mathrm{DRE}^{\mathrm{g}}$

- Offer risk-adapted followup based on initial PSA level

- Followup intervals of 2 years for those initially at risk

- Postpone followup to 8 years in those not at risk

NA

- If PSA $<1 \mathrm{ng} / \mathrm{mL}$ and DRE normal (if done), repeat testing at 2-4year intervals ${ }^{\mathrm{h}}$

- If PSA $1-3 \mathrm{ng} / \mathrm{mL}^{i}$ and DRE normal (if done), repeat testing at $1-2$ year intervals

- If PSA >3 $\mathrm{ng} / \mathrm{mL}^{i}$ or very suspicious DRE, consider indications for biopsy

- If PSA $<3 \mathrm{ng} / \mathrm{mL}$ and DRE normal (if done), and no other indications for biopsy, repeat testing at $1-4-$ year intervals

Based on:

- Low incidence of prostate cancer and prostate cancer mortality

- Lack of evidence for benefit of screening in this age group

- Evidence of harms

This recommendation places:

- Relatively low value on a small and uncertain potential reduction

Canadian

Task Force on

Preventative

Health $(2014)^{8}$
- In prostate cancer mortality

- Relatively higher value on the risk of a false-positive result, unnecessary biopsies, over-diagnosis of prostate cancer, and harms associated with unnecessary treatment

Therefore:

- Risks and benefits of PSA screening and its potential consequences should be discussed with each patient in the context of his preferences

- Men who place a high value on a small potential reduction in mortality and are less concerned with undesirable consequences may choose to be screened 


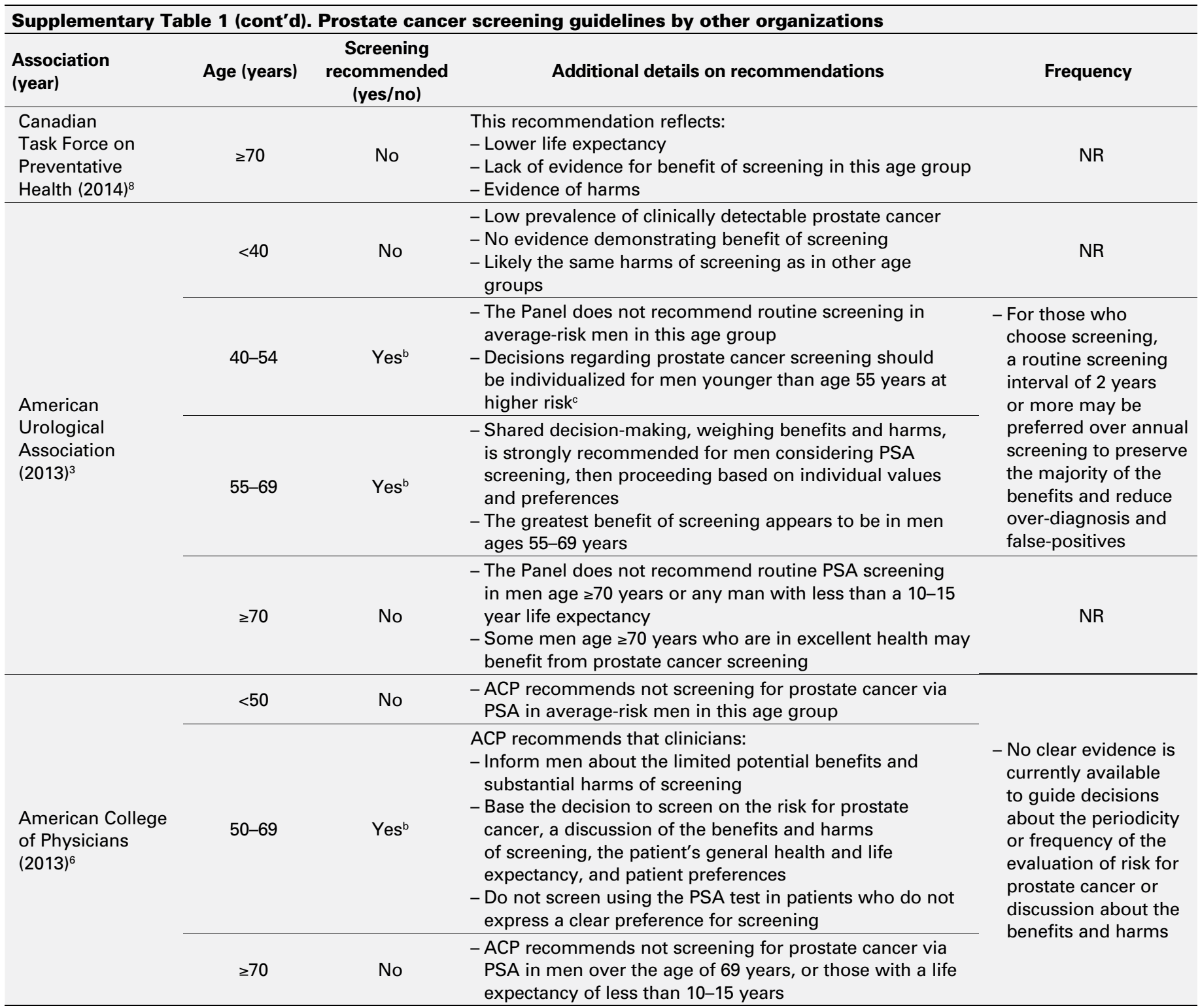

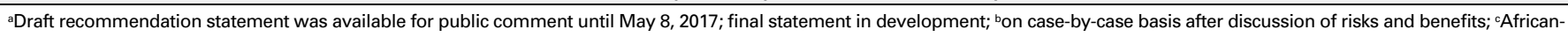

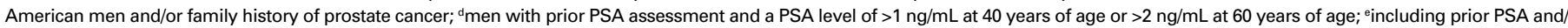

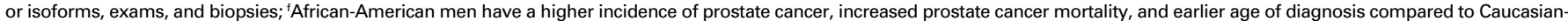

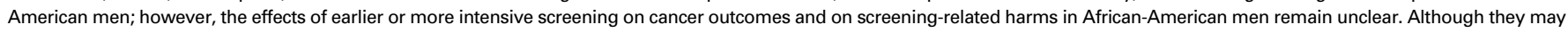
require a higher level of vigilance and different considerations when analyzing the results of screening tests, current data do not support separate screening recommendations for African-

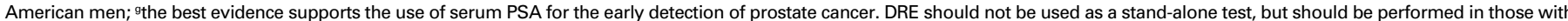

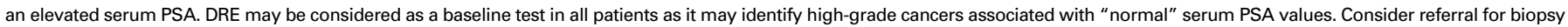

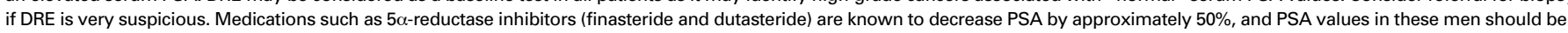

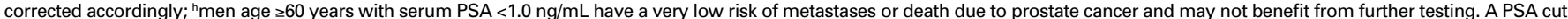
point of $3.0 \mathrm{ng} / \mathrm{mL}$ at age 75 years also low risk of poor outcome; the reported median PSA values for men aged $40-49$ years range from $0.5-0.7 \mathrm{ng} / \mathrm{mL}$, and the 75 th percentile values range

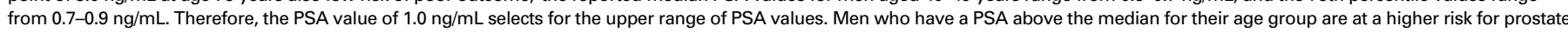
cancer and for the aggressive form of the disease. The higher above the median, the greater the risk; jtesting above the age of 75 years should be done with caution and only in very healthy

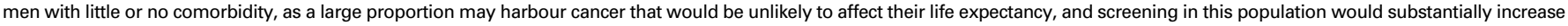

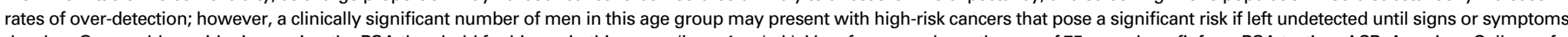

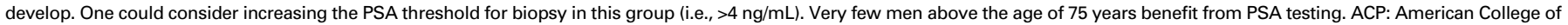
Physicians; BRCA1/2: breast cancer type 1/2 susceptibility gene; DRE: digital rectal exam; NA: not applicable; NR: not reported; PSA: prostate-specific antigen. 